\title{
QUADRO \\ DE REFERÊNCIA \\ DA LIBRAS \\ COMO L2
}

MARCO DE REFERENCIA DE LIBRAS COMO L2

FRAMEWORK OF REFERENCE OF LIBRAS AS L2

\author{
Aline Nunes de Sousa* \\ Juliana Tasca Lohn** \\ Ronice Müller de Quadros*** \\ Larissa Dias**** \\ Nicolly Neves ${ }^{* * * * *}$ \\ Gustavo Gusmão ${ }^{* * * * * *}$
}

Universidade Federal de Santa Catarina

RESUMO: Nós estamos documentando a Língua Brasileira de Sinais (Libras) por meio de diferentes recursos com o objetivo de disponibilizar vídeos e anotações para fins de pesquisa e para fins educacionais. O principal objetivo é sistematizar os dados e os sistemas de buscas dos dados em Libras de forma pública com acesso irrestrito e gratuito. Isso tem empoderado a Libras no Brasil em todos os estados (QUADROS et al., 2016, 2019). Para esta documentação, além do corpus da Libras e demais materiais, estamos estabelecendo interfaces educacionais como para o Ensino da Libras como segunda língua. Todos estes componentes integram o Portal de Libras (UFSC, 2020). Neste artigo, nós apresentaremos os níveis de ensino de Libras desenvolvidos a partir do Quadro Comum Europeu de Referência de Línguas (CONSELHO DA EUROPA, 2001). Nós também analisamos a organização do quadro de referência europeu para o ensino de línguas de sinais - ProSign (LEESON et al., 2016). O objetivo deste projeto é tornar disponível uma descrição dos níveis de proficiência em Libras como segunda língua para oferecer uma referência para o ensino de Libras como segunda língua para os quarenta programas de Libras existentes no Brasil. Também

\footnotetext{
* Professora e pesquisadora da Universidade Federal de Santa Catarina, no Departamento de Libras. E-mail: alinesousa@cce.ufsc.br.

** Professora e pesquisadora da Universidade Federal de Santa Catarina, no Departamento de Libras. E-mail: jujutlsurda@gmail.com.

*** Professora e pesquisadora da Universidade Federal de Santa Catarina, no Departamento de Libras e pesquisadora do CNPQ. E-mail:ronice.quadros@ufsc.br.

**** Estudante do curso de graduação em Letras Libras, bacharelado em tradução/interpretação Libras/Português, na Universidade Federalde Santa Catarina ebolsistaCNPQ.E-mail: diaslarissa67@gmail.com.

***** Estudante do curso de graduação em Letras Libras, licenciatura, na Universidade Federal de Santa Catarina e bolsistaCNPQ. E-mail: nicollyearranildes@gmail.com. 
disponibilizaremos videoaulas de referência, planejadas e ministradas por professores surdos, que podem ser usadas por outros professores de Libras como base dos seus planejamentos de aulas. O artigo apresenta o desenvolvimento deste projeto, que está organizado como material de acesso livre e irrestrito, disponível na nova versão do Portal de Libras.

PALAVRAS-CHAVE: Documentação da Libras. Quadro de referência para a Libras. Ensino de Libras como L2.

RESUMEN: Estamos documentando la Lengua de Señas Brasileña (Libras) a través de diferentes recursos con el objetivo de hacer que los videos y las notas estén disponibles para fines investigativos y educativos. El objetivo principal es sistematizar los datos y las herramientas de búsqueda de datos en Libras de forma pública con acceso abierto. Esto ha empoderado a Libras en todos los estados de Brasil (QUADROS et al., 2016, 2019). Para esta documentación, además del corpus de Libras y de otros materiales, estamos estableciendo interfaces educativas para la enseñanza de Libras como segunda lengua. Todos estos componentes forman parte del Portal de Libras (UFSC, 2020). En este artículo, presentaremos los niveles de enseñanza de Libras desarrollados a partir del Marco Común Europeo de Referencia para las Lenguas (CONSEJO DE EUROPA, 2001). También analizamos la organización del marco de referencia europeo para la enseñanza de lenguas de señas - ProSign (LEESON et al., 2016). El objetivo de este proyecto es poner a disposición una descripción de los niveles de competencia en Libras (L2) para ofrecer una referencia en la enseñanza de Libras como L2 para los cuarenta programas de Libras existentes en Brasil. También ponemos a disposición video de clases como referencia, planificadas e impartidas por profesores sordos, que pueden ser utilizadas por otros profesores de Libras como base para su planificación de clase. El artículo presenta el desarrollo de este proyecto, que se organiza como material de acceso abierto, disponible en la nueva versión del Portal de Libras.

PALABRAS CLAVE: Documentación de Libras. Marco de referencia para Libras. Enseñanza de Libras como L2.

ABSTRACT: We are documenting Brazilian Sign Language (Libras) through different resources with the goal of making available Libras videos and annotations for research and educational purposes. The main objective is to systematize the data and data search tools in Libras in a public way with open access. This has empowered Libras in all states of Brazil (QUADROS et al., 2016, 2019). For this documentation, in addition to the Libras corpus and other materials, we are establishing educational interfaces for the teaching of Libras as a second language. All these components integrate the Libras Portal (UFSC, 2020). In this paper, we will show Libras Teaching Levels, that were inspired by the Common European Framework of Reference for Languages (COUNCIL OF EUROPE, 2001). We also analyzed the organization of the European Framework for Sign Languages - ProSign (LEESON et al., 2016). The goal of this project is to make available the descriptions of the levels of second language proficiency in Libras to offer a reference for all the forty Libras Teaching Programs spread out around the country. Also, there will be available video classes, planned and presented by deaf sign language teachers, that may be used by Libras teachers as a base to plan their own classes. This paper shows the development of this project, which is being designed to be open access, available in the new version of the Libras Portal.

KEYWORDS: Libras documentation. Framework of Reference for Libras. Libras as L2 Teaching.

\section{INTRODUCÃO}

O Quadro de Referência da Libras como L2 integra o projeto Documentação da Libras, que objetiva disponibilizar produções em Libras e materiais relacionados com a Libras para fins de pesquisa e ensino de Libras como segunda língua. A documentação da Libras é abrangente, incluindo desde produções que visam identificar a Libras usada no Brasil por sinalizantes surdos, assim como materiais como o quadro de referência que será apresentado neste artigo, que está voltado para o ensino da Libras como segunda língua.

O Quadro de Referência da Libras configura diretrizes para o ensino de Libras como L2 e objetiva subsidiar os currículos de cursos de Letras Libras e Pedagogia Bilíngue para formação de professores de Libras, tradutores e intérpretes de Libras e Língua Portuguesa e de professores bilíngues de Libras e Língua Portuguesa. A referência curricular para o ensino de Libras partirá do 
quadro de referência das línguas da Europa - Quadro Europeu Comum de Referência para as Línguas ${ }^{1}$ (CONSELHO DA EUROPA, 2001) para a aprendizagem, o ensino e a avaliação.

Neste sentido, o quadro inclui uma composição curricular para servir de referência para as práticas educacionais no ensino de línguas. A metodologia envolveu discussões entre os pesquisadores sobre as competências (conhecimentos, capacidades e atitudes) que são acessadas pelos usuários de uma língua e que são consolidados pelos aprendizes da língua por meio da experiência de uso da língua, que lhes permite comunicar para além das fronteiras linguísticas e culturais.

Para o estabelecimento dos níveis para o ensino de Libras como L2, foi realizado um estudo detalhado dos níveis de referência de ensino de línguas e, após, uma discussão com grupos de trabalhos envolvendo professores de Libras, para, então, estabelecer os níveis de referência para o ensino de Libras. Os níveis estabelecidos são seis, definidos por diferentes atividades linguísticas que são fundamentais para a competência comunicativa: a recepção (compreensão oral e leitura), interação e produção (produção oral e produção de textos escritos).

A partir do QECR, o Quadro de Referência da Libras foi organizado com o intuito de fomentar a criação de ambientes que sejam espaços de aprendizagem e que se tornem espaços reais de comunicação. Essa referência, portanto, incentiva situações de comunicação autêntica entre pessoas de diferentes estados, em várias universidades e instituições de ensino do país. O material serve também para o ensino da Libras como segunda língua na rede regular de ensino, considerando a educação bilíngue para surdos, servindo como referência aos professores para que tenham a possibilidade de planejar suas aulas de forma mais estruturada e técnica, considerando a transparência e a comparabilidade dos processos de ensino e aprendizagem correspondentes a cada nível de competência alcançado. Nesta aplicação, as famílias das crianças surdas, assim como a comunidade escolar, na sua grande maioria ouvinte, se beneficia com as referências de ensino de Libras como segunda língua propostas neste quadro. Isso também permitirá a mobilidade acadêmica entre os alunos dos cursos de Letras Libras e dos cursos de Pedagogia Bilíngue. Além do QECR, foi considerado o ProSign, que é um desdobramento do QECR para referência para o ensino de línguas de sinais européias. O ProSign segue basicamente a mesma proposta do QECR, mas incluindo aspectos específicos das línguas de sinais.

Um professor de Português ou de Inglês no Brasil tem acesso às diretrizes, conteúdos, competências e habilidades que devem ser ensinadas na escola porque contam com uma Base Nacional Comum Curricular - BNCC (BRASIL, 2017). No entanto, os professores de Libras ainda não dispõem desse tipo de orientação para o ensino da língua, o que torna o processo bastante complexo no sentido de cada docente ter de fazer suas próprias escolhas e tomar decisões sozinho na elaboração de seu planejamento. O uso de referências do português ou outras línguas pode não ser apropriado, as línguas de sinais envolvem modalidade distinta das línguas orais, portanto, nem sempre as habilidades a serem desenvolvidas são as mesmas. Dentro desse contexto, a elaboração de uma matriz que desenhe as competências e habilidades a serem desenvolvidas para o ensino de Libras como segunda língua é fundamental, sobretudo se considerarmos as políticas públicas de inclusão vigentes no Brasil, com vistas à educação bilíngue de surdos. Também se torna fundamental a proposição de referências curriculares de ensino de Libras como primeira língua (L1), considerando o ensino da língua aos alunos surdos. No entanto, o quadro proposto aqui tem como foco exclusivamente o ensino de Libras como L2, ou seja, para aqueles que já contam com uma língua e irão aprender a Libras como segunda língua. Temos como objetivo futuro oferecer também um quadro de referência curricular de ensino de Libras como L1.

Além disso, o espaço do Quadro de Referência da Libras no Portal de Libras inclui videoaulas ministradas pelos próprios professores de Libras do projeto, onde apresentam aulas de referência. Esse espaço será aberto também para outros professores de Libras como segunda língua do país compartilharem suas aulas.

\section{AS REFERÊNCIAS DO CONSELHO EUROPEU PARA O ENSINO DE SEGUNDA LÍNGUA}

\subsection{O QUADRO COMUM EUROPEU COMUM DE REFERÊNCIA PARA AS LÍNGUAS (QECR)}

\footnotetext{
${ }^{1}$ Doravante, QECR.
} 
O Quadro Europeu Comum de Referência para as Línguas foi publicado em 2001 pelo Conselho da Europa e é utilizado em muitos países da Europa (e de fora dela) como uma referência no ensino e na avaliação de segunda língua (L2) e língua estrangeira (LE). Ele fornece uma base comum para a elaboração de conteúdos programáticos, orientações curriculares, testes, avaliações, livros-texto entre outros materiais para o ensino de L2/LE.

Esse quadro descreve o que os aprendizes devem aprender a fazer para usar uma língua com fins comunicativos e quais conhecimentos e habilidades eles precisam desenvolver para agir/comunicar de forma eficiente, abordando, inclusive, questões culturais do contexto da L2/LE. O quadro também estabelece níveis de proficiência que permitem avaliar e medir o progresso dos estudantes em cada estágio da aprendizagem da L2/LE e ao longo de sua vida enquanto aprendizes dessa língua.

Ele foi pensado para ser usado tanto por profissionais relacionados ao ensino e avaliação de línguas (L2/LE) quanto por aprendizes e foi escrito com dois objetivos principais:

1. Encorajar todos os que trabalham na área das línguas vivas, incluindo os aprendentes, a refletirem sobre questões como:

- O que fazemos exactamente quando falamos ou escrevemos uns aos outros?

- O que nos permite agir assim?

- O que é que precisamos de saber a este respeito para tentarmos utilizar uma língua nova?

- Como definimos os nossos objetivos e avaliamos o nosso progresso entre a ignorância total e o domínio efectivo da língua estrangeira?

- Como se processa a aprendizagem da língua?

- Que podemos fazer para nos ajudarmos a nós próprios e aos outros a melhor aprendermos uma língua?

2. Facilitar a troca de informação entre os que trabalham nesta área e os aprendentes, de modo a que estes possam ser informados sobre o que deles se espera, em termos de aprendizagem, e como poderão ser ajudados. (CONSELHO DA EUROPA, 2011, p. 11)

Entretanto, o quadro não foi pensado para ser normativo, a ponto de engessar as práticas de ensino e aprendizagens de L2/LE com suas diretrizes. A função do quadro não é prescrever os objetivos de aprendizagem que os estudantes precisam atingir nem os métodos de ensino que os professores devem utilizar. A intenção do Conselho Europeu, por meio do quadro, foi melhorar a qualidade da comunicação entre os cidadãos europeus de diversas realidades linguísticas e culturais, já que uma boa comunicação leva a uma maior mobilidade, intercâmbio, compreensão recíproca e cooperação, promovendo, assim, uma cidadania democrática.

Dessa forma, o Conselho da Europa (2001, p.12) considera importante que os organizadores da aprendizagem das línguas se baseiem nas “[...] necessidades, motivações, características e recursos dos aprendentes”, respondendo a questões como:

- O que é que os aprendentes precisam de fazer com a língua?

- O que é que eles precisam aprender para serem capazes de usar a língua para esses fins?

- O que é que os leva a aprender?

- Que espécie de pessoas são (idade, sexo, meio social e nível de educação, etc.)?

- Que saberes, capacidades e experiência possuem os professores?

- Que acesso têm a manuais, obras de referência (dicionários, gramáticas, etc.), suportes audiovisuais e informáticos?

- Quanto tempo podem (querem ou são capazes de) dedicar à aprendizagem de uma língua? (CONSELHO DA EUROPA, 2011, p. 12)

Assim, a partir de uma análise da situação de ensino/aprendizagem da L2/LE é que é possível definir objetivos de aprendizagem realistas, em função das necessidades, características e recursos dos estudantes e dos professores. 


\subsection{PROSIGN}

O ProSign se trata de um projeto (e de um documento) elaborado para estabelecer critérios para a proficiência em língua de sinais para fins profissionais, focando no ensino de língua de sinais em programas de Estudos Surdos e Interpretação de Língua de Sinais. O documento foi produzido por vários especialistas, engajados na avaliação, testagem e validação dos descritores do QECR para o ensino de línguas de sinais, em consonância com os níveis de referência do QECR. O documento, além de estar na versão escrita (LEESON et al., 2016), está disponível em ISL (língua de sinais internacional) na página web do projeto (ECML/CELV, 2020).

Esse documento serve como um marco de referência para professores de línguas de sinais, formadores de professores de línguas de sinais e desenvolvedores de currículos de línguas de sinais em ambientes educacionais. Ele também serve como suporte para organizações não governamentais como associações e federações de surdos e de intérpretes de línguas de sinais.

Foi uma tarefa complexa da equipe para assegurar que os descritores pensados inicialmente para o QECR descrevessem uma progressão gradual para línguas de modalidade visual-gestual sem a modalidade escrita. Enquanto alguns descritores do QECR tiveram de sofrer pequenas adaptações na descrição, outros sofreram uma reestruturação a fim de se adequarem à modalidade específica das línguas de sinais. Além disso, foram tomadas como base pesquisas na área de linguística e aquisição de línguas de sinais como segunda língua para se estabelecer os descritores para a proficiência em língua de sinais. Foi realizado um grande encontro em 2015, na Áustria, para a validação desses descritores e foram realizadas consultas a professores experientes de língua de sinais como segunda língua que não estavam no encontro.

No contexto brasileiro, a equipe do subprojeto Ensino de Libras como L2, do projeto Documentação da Libras (UFSC/CNPq), composta por professores-pesquisadores surdos, professores-pesquisadores ouvintes, estudantes de graduação surdos e ouvintes está realizando o estudo e a adaptação dos descritores utilizados para língua de sinais.

Por fim, após a publicação dos referidos descritores na página web do Portal de Libras (LIBRAS, 2020), a comunidade surda brasileira (professores de libras como segunda língua, linguistas, usuários da Libras como segunda língua, entre outros) poderá atuar colaborativamente neste trabalho, enviando avaliações, críticas e sugestões à equipe.

\subsection{NÍVEIS COMUNS DE REFERÊNCIA}

O QECR organiza as competências para um falante de segunda língua em seis níveis. Esses níveis se baseiam em testes reconhecidos de certificação que já eram utilizados na época da criação do quadro. Os descritores se baseiam no que professores de língua materna e não materna consideraram mais úteis e pertinentes. É importante lembrar que esses descritores são recomendações dos elaboradores, e não uma prescrição, os quais deverão sempre ser adaptados aos contextos locais de ensino da língua.

O QECR (CONSELHO DA EUROPA, 2001) apresenta três níveis de conhecimento de língua - e seis subníveis. O nível A representa o falante/usuário como "utilizador elementar", trata de um aprendiz em nível básico. No nível A, existem duas subclassificações: o A1 ("iniciação") e o A2 ("elementar"). Seguidamente, se encontra o nível B, o do "utilizador independente”. Esse nível se divide em dois subníveis: B1 ("limiar" ou "intermediário") e B2 ("vantagem” ou "pós-intermediário"). Por fim, existe o nível C, que qualifica o falante/usuário como "utilizador proficiente" e está subdividido em C1 ("autonomia" ou "avançado") e C2 ("maestria" ou "proficiente"). A seguir, temos um quadro com a descrição básica de cada um desses seis subníveis. 
NÍVEL

A1

A2

B1

B2

$\mathrm{C} 1$

$\mathrm{C} 2$

\section{DESCRIÇÃO}

Definido como sinalizante em iniciação. Pode-se dizer que o utilizador está iniciando o aprendizado na língua de sinais, aprendendo os aspectos básicos da língua como expressões faciais, configuração de mãos etc.

Classificado como utilizador elementar, o indivíduo começa a produzir frases simples. O sinalizante já conhece as características básicas da língua e as utiliza em contextos simples.

Descrito como utilizador limiar ou intermediário, consegue interagir brevemente sobre assuntos de interesse pessoal e familiares. O sinalizante está aprendendo mais aspectos da língua de sinais. Seu interlocutor precisa manter uma sinalização pausada.

Nomeado como utilizador em vantagem ou pós-intermediário, possui a capacidade de interação mais aprofundada. Já compreende profundamente os aspectos linguísticos da língua de sinais e os utiliza em frases mais complexas.

Intitulado utilizador em autonomia ou avançado. A pessoa já compreende muito bem a língua de sinais e sinaliza de forma natural. Consegue argumentar com um ótimo senso argumentativo e crítico.

Descrito como utilizador em maestria ou proficiente. O sinalizante consegue utilizar a língua de sinais em diversos âmbitos. Apresenta um senso crítico e argumentativo em nível acadêmico. O sinalizante conhece e utiliza as variações linguísticas como um sinalizante nativo.

Quadro 1: Descrição dos níveis de proficiência linguística para línguas de sinais

Fonte: Adaptado de Conselho da Europa (2016)

Além desses subníveis, o QECR apresenta alguns outros subníveis, a saber: A2+ (entre o A2 e o B1), B1+ (entre o B1 e o B2) e B2+ (entre o B2 e o C1). No Portal de Libras eles não vão aparecer no plano principal, mas serão incluídos dentro das abas dos níveis principais.

De acordo com o quadro europeu (CONSELHO DA EUROPA, 2001), o subnível A2+ corresponde a um desempenho denominado Elementar Forte. O utilizador, nesse nível, tem uma participação mais ativa na conversação, desde que apoiada pelo interlocutor, mas ainda com certas limitações.

O subnível B1+ corresponde ao desempenho Limiar Forte. Dois aspectos característicos principais do nível B1 continuam presentes: (1) a capacidade de manter a interação e chegar ao que se quer em uma gama variada de contextos e (2) a capacidade de lidar de forma flexível com problemas do dia-a-dia. A esses dois aspectos foram adicionados, no nível B1+, alguns descritores que apontam para a troca de alguma quantidade de informação.

O subnível B2+ corresponde ao desempenho Vantagem Forte. Nesse subnível, mantém-se a atenção à argumentação, à eficácia do discurso social e à consciencialização linguística presentes no nível B2. Entretanto, no B2+, há um destaque para a argumentação e para o discurso social, que pode ser também interpretado como uma atenção maior às capacidades discursivas. Esse novo grau de competência discursiva revela-se na condução da conversação (estratégias de cooperação). 


\section{PROCEDIMENTOS METODOLÓGICOS DO PROJETO}

\subsection{A ADAPTAÇÃO DAS ATIVIDADES LINGUÍSTICAS E SEUS DESCRITORES PARA A LIBRAS}

O QECR traz descritores do tipo "é capaz de" ("can do descriptors”) para recepção (compreensão oral e leitura), interação e produção (produção oral e produção de textos escritos), do nível A1 ao C2. Conforme mencionado anteriormente, o primeiro passo da equipe brasileira foi estudar o QECR (versão em português de Portugal e versão em inglês) e o modelo do ProSign (versão em inglês e em ISL). Após o estudo, chegou-se a uma proposta de organização das competências para as atividades linguísticas de recepção (compreensão em sinais e compreensão de leitura), interação e produção em língua de sinais brasileira (produção sinalizada e produção escrita), as quais se encontram nos quadros a seguir.

\section{A1 - Utilizador Básico}

\begin{abstract}
ATIVIDADE
LINGUÍSTICA
\end{abstract}

COMPREENSÃO

LEITURA

INTERAÇÃO

PRODUÇÃO

ESCRITA

LINGUÍSTICA

COMPREENSÃO

\section{DESCRITORES}

É capaz de reconhecer palavras e expressões simples, de uso corrente, relacionadas ao sinalizante como, por exemplo, sobre família e contextos em que ele está inserido, desde que o interlocutor sinalize de forma clara e pausada.

É capaz de compreender nomes conhecidos, palavras e frases muito simples, por exemplo, em avisos, cartazes ou folhetos.

É capaz de se comunicar de forma simples, desde que o interlocutor se disponha a repetir ou sinalizar a mesma mensagem usando outros sinais, em um ritmo mais lento, e ajude o sinalizante a formular aquilo que ele gostaria de dizer. Também é capaz de perguntar e de responder perguntas simples sobre assuntos conhecidos ou relativos a temas de necessidade imediata.

É capaz de utilizar expressões e frases simples para descrever o local onde o sinalizante vive e as pessoas que ele conhece.

É capaz de escrever um postal simples e curto para, por exemplo, descrever as férias. É capaz de preencher uma ficha com dados pessoais como, por exemplo, em um hotel, informando o nome, a moradia e a nacionalidade.

Quadro 2: Descritores do Nível A1

Fonte: Leeson et al. (2016)

\section{A2 - Utilizador Básico}

\section{DESCRITORES}

É capaz de compreender expressões e palavras de uso mais frequente, relacionados com aspectos de interesse pessoal como, por exemplo, família, compras, trabalho e meios em que o sinalizante vive. Consegue compreender o essencial de mensagens simples, sendo curtas e precisas, como, por exemplo, em um anúncio. 
É capaz de ler textos e cartas pessoais curtas e simples. Consegue encontrar uma informação previsível e concreta em textos simples de uso frequente como, por exemplo, em anúncios, folhetos, ementas e quadros de horários.

INTERAÇÃO

PRODUÇÃO

ESCRITA

ATIVIDADE LINGUÍSTICA

COMPREENSÃO

LEITURA

INTERAÇÃO

PRODUÇÃO
É capaz de se comunicar em situações simples, de rotina do dia-a-dia, sobre assuntos e atividades habituais que exijam apenas uma troca de informação simples e direta. É capaz de participar de breves trocas de informações, apesar de não compreender o suficiente para manter a conversa.

É capaz de utilizar uma série de expressões e frases para sinalizar, de forma simples, em contextos sobre a família, sobre outras pessoas, das condições de vida, do andamento escolar e do trabalho atual ou mais recente.

É capaz de escrever notas e mensagens curtas e simples sobre assuntos de necessidade imediata. É capaz de escrever uma carta pessoal muito simples, por exemplo, para agradecer alguma coisa a alguém.

Quadro 3: Descritores do Nível A2

Fonte: Leeson et al. (2016)

\section{B1 - Utilizador Independente}

\section{DESCRITORES}

É capaz de compreender os pontos essenciais de uma sequência sinalizada que aborde assuntos do trabalho, da escola e lazer. Consegue compreender os pontos principais de muitos programas de vídeo e de televisão, sobre temas atuais ou assuntos de interesse pessoal ou profissional, quando o interlocutor sinaliza de forma relativamente lenta e clara.

É capaz de compreender textos em que predomine uma linguagem do dia-a-dia ou relacionada ao trabalho. É capaz de compreender descrições de acontecimentos, sentimentos e vontades, em cartas pessoais, por exemplo.

É capaz de lidar com a maior parte das situações que podem surgir durante uma ida para um lugar em que a língua é sinalizada. É capaz de entrar em uma conversa, sem preparação prévia, durante uma interação sobre assuntos conhecidos, de interesse pessoal ou relacionados ao dia-adia como, por exemplo, sobre família, passatempos, trabalho, viagens e assuntos da atualidade.

É capaz de articular expressões de forma simples para descrever experiências e acontecimentos, sonhos, desejos e ambições. É capaz de explicar ou justificar opiniões e planos. Consegue contar uma história, relatar o enredo de um livro ou de um filme e descrever reações. 
ESCRITA

E capaz de escrever um texto articulado de forma simples sobre assuntos conhecidos ou de interesse pessoal e de escrever cartas pessoais descrevendo experiências e impressões.

Quadro 4: Descritores do Nível B1

Fonte: Leeson et al. (2016)

\section{B2 - Utilizador Independente}

ATIVIDADE

LINGUÍSTICA

COMPREENSÃO

LEITURA

INTERAÇÃO

PRODUÇÃO

ESCRITA

ATIVIDADE LINGUÍSTICA

COMPREENSÃO

\section{DESCRITORES}

É capaz de compreender exposições longas e palestras. Consegue acompanhar partes mais complexas de uma argumentação, desde que o tema seja relativamente familiar. Consegue compreender a maior parte dos noticiários e outros programas informativos na televisão. É capaz de compreender a maior parte dos filmes, desde que seja utilizada a língua padrão.

É capaz de ler artigos e reportagens sobre assuntos contemporâneos em relação as quais os autores adotam determinadas atitudes ou pontos de vista particulares. Compreende textos literários contemporâneos em prosa.

É capaz de conversar com a fluência e espontaneidade suficientes para tornar possível a interação fluida com falantes nativos. É capaz de fazer uso da palavra em uma discussão que tenha lugar em contextos conhecidos, apresentando e defendendo os seus pontos de vista.

É capaz de sinalizar de forma clara e detalhada sobre uma gama de assuntos relacionados ao interesse do sinalizante. Consegue explicar um ponto de vista sobre um assunto, apresentando as vantagens e desvantagens de diferentes opções.

É capaz de escrever um texto claro e detalhado sobre uma gama de assuntos relacionados ao interesse do sinalizante. Consegue redigir um texto expositivo ou um relatório, transmitindo informações ou apresentando razões a favor ou contra um determinado ponto de vista. É capaz de escrever cartas evidenciando determinados acontecimentos ou experiências.

Quadro 5: Descritores do Nível B2

Fonte: Leeson et al. (2016)

\section{C1 - Utilizador Proficiente}

\section{DESCRITORES}

É capaz de compreender uma exposição longa, mesmo que não esteja claramente estruturada ou quando a articulação entre as ideias esteja apenas implícita. Consegue compreender programas de televisão e filmes sem grande dificuldade. 
LEITURA

INTERAÇÃO

PRODUÇÃO

ESCRITA

ATIVIDADE

LINGUÍSTICA

COMPREENSÃO

LEITURA

INTERAÇÃO

PRODUÇÃO
É capaz de compreender textos longos e complexos, literários e não literários, e distinguir estilos. Compreende artigos especializados e instruções técnicas longas, mesmo quando não se relacionam a área de conhecimento do sinalizante.

É capaz sinalizar de forma espontânea e fluente, sem dificuldade aparente em encontrar as expressões adequadas. É capaz de utilizar a língua de maneira flexível e eficaz para fins sociais e profissionais. Consegue formular ideias e opiniões com precisão e adequa o discurso aos interlocutores.

É capaz de apresentar descrições claras e detalhadas sobre temas complexos que integram subtemas, desenvolvendo aspectos particulares e chegando a uma conclusão apropriada.

É capaz de se expressar de forma clara e bem estruturada, apresentando os pontos de vista com certo grau de elaboração. Consegue escrever cartas, comunicações ou relatórios sobre assuntos complexos, pondo em evidência os aspectos mais importantes, assim como escrever no estilo que considera apropriado para o leitor que tenha em mente.

Quadro 6: Descritores do Nível C1

Fonte: Leeson et al. (2016)

\section{C2 - Utilizador Proficiente}

\section{DESCRITORES}

É capaz de compreender com facilidade qualquer tipo de enunciado sinalizado, tanto face a face como através dos meios de comunicação, mesmo quando se sinaliza depressa, como a velocidade dos sinalizantes nativos, sendo apenas necessário algum tempo para se familiarizar com a variação dos sinais (sotaque).

É capaz de ler com facilidade praticamente todas as formas de texto escrito, incluindo textos mais abstratos, linguística ou estruturalmente complexos, tais como manuais, artigos especializados e obras literárias.

É capaz de participar sem esforço em qualquer conversa ou discussão e mesmo utilizar expressões idiomáticas e coloquiais. Consegue se expressar fluentemente e transmitir com precisão pequenas diferenças de sentido. Sempre que tem um problema, é capaz de voltar atrás, contornar a dificuldade e reformular, sem que tal dificuldade seja notada.

É capaz de, sem dificuldade e fluentemente, fazer uma exposição ou desenvolver uma argumentação em um estilo apropriado ao contexto e com uma estrutura lógica tal que ajude o interlocutor a identificar e a memorizar os aspetos mais importantes. 
É capaz de escrever textos em um estilo fluente e apropriado. Consegue redigir de forma estruturada cartas complexas, relatórios ou artigos que apresentem uma situação com uma

ESCRITA estrutura lógica que ajude o leitor a entender os pontos essenciais e memorizá-los. É capaz de formular resumos e recensões de obras literárias e de âmbito profissional.

Quadro 7: Descritores do Nível C2

Fonte: Leeson et al. (2016)

\subsection{O PROCESSO DE TRADUÇÃO E ADAPTAÇÃO DOS DESCRITORES ESPECÍFICOS PARA A LIBRAS}

Na década de 1960, de acordo com Zipser e Polchlopek (2009), a tradução transitava entre duas perspectivas: ser fiel x ser livre. Já nos anos de 1970, a tradução pretendia ser compreensível para o leitor/interlocutor, bem como respeitar suas características culturais. Essa era a visão funcionalista (NORD, 2016), a qual entende a tradução como uma atividade contextualizada.

Nord (2016) menciona que o primeiro passo do tradutor quando se depara com um texto fonte é estudar sua função, realizar buscas terminológicas, materiais envolvidos, localizar leituras do gênero em questão, para então pensar em sua primeira proposta de tradução. Outro passo importante é sempre pensar em seu público alvo, organizando a estrutura do texto traduzido para que esse público possa compreendê-lo de modo eficaz, alcançando o objetivo comunicativo pensado pelo autor/emissor do texto fonte. Para isso, é importante também identificar as questões culturais do texto fonte e traduzi-las (ou adaptá-las) de modo que os leitores compreendam de forma adequada a intenção comunicativa do autor/emissor do texto fonte. Foram esses princípios funcionalistas que embasaram o processo de tradução/adaptação do QECR para a versão brasileira, na Libras.

Inicialmente foi realizado, pela equipe do Projeto de Libras L2, um processo de estudo do QECR nas suas versões inglesa e portuguesa $^{2}$, para, posteriormente, se fazer a adaptação dos descritores específicos para a Libras e a tradução para a Libras e para o português do Brasil. Devido à complexidade desse estudo, foi necessário também assistir, algumas vezes, aos vídeos em ISL, disponíveis no site do ProSign, para contextualizar os descritores e compreendê-los com maior precisão.

Em seguida, foi realizada a primeira proposta de glosas pela bolsista ouvinte do projeto ${ }^{3}$, para a posterior gravação em vídeo dos descritores da Libras pelos estudantes surdos do projeto. Após a primeira proposta de glosas, a bolsista surda ${ }^{4}$ então realizava a revisão dessas glosas. Após o estudo das bolsistas, todos os integrantes do grupo (professores e alunos) se reuniam para discutir as dúvidas e trabalhar na versão final das glosas. Em algumas situações, por exemplo, o quadro trazia descritores com elementos gramaticais específicos da língua do quadro em questão (inglês ou português de Portugal), não ficando viável realizar uma "tradução literal" desses elementos - como, por exemplo, "elementos de coesão" - para a Libras. Nesses momentos, a equipe precisou realizar uma adaptação incluindo exemplos da Libras, bem como aspectos culturais, como se vê no quadro a seguir.

\begin{tabular}{c|c} 
TEXTO EM PORTUGUÊS BRASILEIRO & GLOSAS PARA A TRADUÇÃO PARA A LIBRAS \\
\hline Dirigindo-se a uma audiência & EM PE AUDITÓRIO \\
$\begin{array}{c}\text { Consegue sinalizar uma frase muito curta e ensaiada. Por exemplo: } \\
\text { apresentar uma conferência simples, introduzir alguém ou propor } \\
\text { um brinde. }\end{array}$ & $\begin{array}{c}\text { SINALIZAR FRASE CURTA, ANTES TREINAR. } \\
\text { VIR-E-VIRAR PESSOA-HOMENAGEM APRESENTAR } \\
\text { EXPLICAR BÁSICO, }\end{array}$ \\
Quadro 8: Exemplo de Glosas - Vídeo 1 - Nível Al \\
Fonte: Os autores
\end{tabular}

\footnotetext{
${ }^{2}$ De Portugal.

${ }^{3}$ Larissa Dias.

${ }^{4}$ Nicolly Neves.
} 
Foi principalmente durante o estudo e discussão da tradução dos descritores, em grupo, que foram utilizados os fundamentos da teoria funcionalista na perspectiva de Nord (2016). Seguiu-se nessa linha de tradução para não apenas fazer uma tradução literal do quadro europeu, mas manter seu objetivo de comunicar aos leitores (sobretudo estudantes e professores de L2) o que utilizadores de uma L2 são capazes de fazer em cada nível de competência para o uso dessa língua. Assim, o quadro de referência de Libras L2 pretende, também, comunicar ao leitor brasileiro - sobretudo a professores e estudantes de Libras como L2, principais utilizadores do quadro - o que um utilizador de Libras L2 é capaz de fazer em Libras em determinada competência e em determinado nível.

Após o estudo e discussão da versão final das glosas, a estudante surda gravava os vídeos em Libras, como atriz-tradutora, os quais eram editados por outro bolsista surdo ${ }^{5}$ do projeto, o qual acabou também, posteriormente, se tornando ator-tradutor dos níveis mais avançados do projeto. Esses vídeos seriam revisados pelas professoras participantes do projeto. Se necessário, haveria regravação, até se chegar à versão mais adequada para ser postada no Portal de Libras. Como são estudantes em formação (e não tradutores profissionais), a etapa de estudo e preparação das glosas e gravação dos vídeos demorou mais do que o planejado no projeto inicial. Apesar disso, percebe-se o quanto os estudantes participantes do projeto amadureceram com relação aos seus conhecimentos sobre a estrutura da Libras, sobre o ensino de L2 e sobre os procedimentos de tradução para a Libras. A seguir está a organização em que os vídeos vão aparecer no portal de Libras.

\begin{tabular}{|c|c|}
\hline COMPETÊNCIAS/ATIVIDADES & TÍTULOS DO DESCRITORES ESPECÍFICOS \\
\hline \multirow{8}{*}{ Produção } & 1 - Dirigindo-se a uma audiência \\
\hline & 2 - Compensação \\
\hline & 3 - Monitoramento e reparo \\
\hline & 4 - Produção geral \\
\hline & 5 - Planejamento \\
\hline & 6 - Anúncios públicos \\
\hline & 7 - Discurso monológico descrevendo uma experiência \\
\hline & 8 - Discurso monológico relatando um caso \\
\hline \multirow{6}{*}{ Compreensão } & 10 - Compreensão em uma mídia visual \\
\hline & 11 - Identificar sugestões e deduções na sinalização \\
\hline & 12 - Compreensão geral \\
\hline & 13 - Entendimento de conversas de sinalizantes nativos \\
\hline & 14 - Assistindo anúncios e instruções \\
\hline & 15 - Assistindo vídeos \\
\hline \multirow{5}{*}{ Interação em Sinais } & 16 - Conversação \\
\hline & 17 - Discurso informal (entre amigos) \\
\hline & 18 - Troca de informações \\
\hline & 19 - Entrevistar e ser entrevistado (a) \\
\hline & 20 - Interação em sinais geral \\
\hline
\end{tabular}

${ }^{5}$ Gustavo Gusmão. 


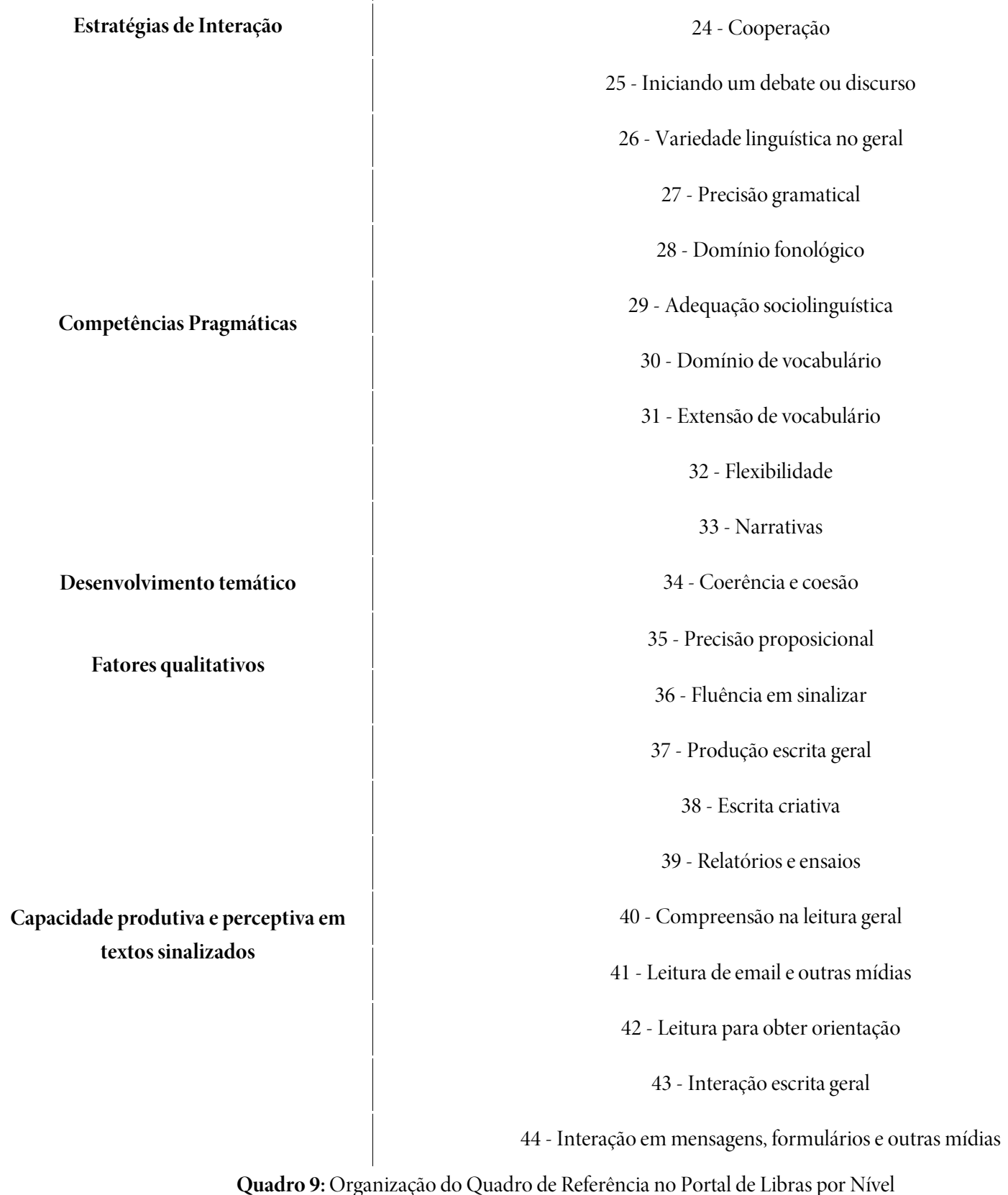

Quadro 9: Organização do Quadro de Referência no Portal de Libras por Nível

Fonte: Os autores

Em cada nível, do A1 ao C2, o usuário do Portal de Libras verá os vídeos dos descritores em Libras para cada um dos títulos mencionados acima, bem como sua tradução para o português brasileiro. Dependendo do nível, não há vídeo para determinados descritores e, em alguns casos, é o mesmo vídeo para mais de um nível, pois alguns descritores se repetem.

Além desses vídeos, no portal haverá a tradução para a Libras dos objetivos gerais do projeto e da descrição geral de cada nível de proficiência (Quadro 1), bem como a tradução dos descritores gerais para cada atividade linguística (Quadros 2 a 7).

3.3 O ENSINO DE LIBRAS L2: PRODUÇÃO DE VIDEOAULAS DE REFERÊNCIA BASEADAS NO QUADRO BRASILEIRO 
No Brasil, a Libras foi reconhecida legalmente como língua das comunidades de pessoas surdas em 2002 por meio da Lei 10.436 (BRASIL, 2002). Essa lei foi o primeiro documento legal brasileiro a tratar do ensino de Libras como segunda língua. De acordo com o seu artigo $4^{\circ}$ :

O sistema educacional federal e os sistemas educacionais estaduais, municipais e do Distrito Federal devem garantir a inclusão nos cursos de formação de Educação Especial, de Fonoaudiologia e de Magistério, em seus níveis médio e superior, do ensino da Língua Brasileira de Sinais - Libras, como parte integrante dos Parâmetros Curriculares Nacionais - PCNs, conforme legislação vigente. (BRASIL, 2002, art. 4o)

Essa lei foi regulamentada pelo decreto 5626 em 2005 (BRASIL, 2005), e esse decreto trouxe um maior detalhamento sobre o ensino de Libras como L2 e sobre a formação de professores para o ensino de Libras como L2. Entretanto, por ser um decreto e não um documento pedagógico (como um referencial ou orientação curricular), ele trata esses assuntos de forma geral, não sendo suficiente para subsidiar a prática pedagógica cotidiana no ensino de Libras L2, seja na Educação Básica, seja no Ensino Superior.

Muito antes da lei e do decreto acima mencionados serem publicados, o ensino de Libras como L2 já era uma prática em nosso país. Desde a década de 1980, as associações de surdos, federações de surdos, escolas de surdos e ministérios e pastorais de igrejas vem trabalhando com o ensino de Libras como segunda língua para ouvintes, tanto com instrutores ouvintes quanto com instrutores surdos. Entretanto, a formação acadêmica para professores de Libras só tem início com a criação do primeiro curso de licenciatura em Letras Libras pela Universidade Federal de Santa Catarina em 2006. Ao longo dos últimos anos, várias outras universidades foram criando cursos de graduação em Letras Libras, presenciais e semipresenciais e, atualmente, temos cursos de Letras Libras em todos os estados da federação, formando professores Libras tanto para o ensino de Libras como primeira quanto como segunda língua.

O ensino de Libras como segunda língua no Brasil durante muito tempo priorizou uma perspectiva lexicalista (ensino de palavras do português relacionadas a sinais da Libras) e, posteriormente, uma perspectiva estruturalista (ensino da estrutura da Libras) - cf. Bernardino, Pereira e Passos (2018). Muitos cursos criavam suas próprias apostilas e seus próprios currículos, sem diretrizes oficiais para o ensino da Libras como L2, até que, em 2004, o MEC, em parceria com a FENEIS lança um programa de formação de instrutores de Libras (Curso de capacitação para Instrutores - Metodologia para o Ensino de Libras) e um material didático para o ensino de Libras para ouvintes em nível básico, o livro Libras em Contexto: Curso Básico, em duas versões: uma para o estudante (FELIPE, 2007) e outra para o professor (FELIPE; MONTEIRO, 2006). Esse segundo se trata de um material organizado para servir de apoio ao instrutor de Libras no planejamento e preparação das aulas e atividades extraclasses. Esse material trazia uma perspectiva de ensino de língua mais comunicativa, dialógica e contextualizada e menos centrada na gramática e no léxico, como grande parte das propostas de ensino de Libras até então. Infelizmente, esse material só contempla o ensino do nível básico da Libras. Alguns outros materiais surgiram após a publicação do Libras em Contexto, numa linha mais comunicativa de ensino de língua, porém a maioria deles ficou centrada no nível básico (como Pimenta e Quadros, 2006).

Existe, portanto, uma lacuna no Brasil em termos de referencial curricular e material didático para o ensino de Libras como segunda língua em todos os níveis de competência de um utilizador - do elementar ao proficiente. Acreditamos, portanto, que o QECR, com sua perspectiva funcionalista de língua e de ensino de língua, é capaz de preencher parte dessa lacuna ao nos embasar para descrevermos as competências de um utilizador de Libras como segunda língua em cada um dos seus estágios de domínio dessa língua. O Quadro de Referência da Libras poderá servir de orientação para criação de currículos para alunos ouvintes da Educação Básica, do Ensino Superior (nas disciplinas básicas de Libras) e de cursos livres, bem como para a criação de currículos para a formação de professores de Libras e de intérpretes-tradutores de Libras (nos cursos de Letras Libras) e para a criação de materiais didáticos para o ensino dos diferentes níveis de competência na Libras. Além disso, o quadro pode servir de parâmetro para a criação de testes de proficiência e nivelamento em Libras.

Além da proposição do quadro de competências em si, o Projeto Libras L2 tem como objetivo fornecer, no Portal de Libras, exemplares de aulas-modelo de Libras como L2 para cada nível, ministradas por professores surdos da UFSC (pesquisadores no ensino de Libras) e planejadas por toda a equipe do projeto. Além disso, o portal será uma plataforma aberta, na qual professores 
de Libras do Brasil inteiro poderão criar, postar e comentar videoaulas referentes ao ensino de cada nível de proficiência da Libras, criando assim uma grande rede colaborativa de professores para o ensino de Libras como L2 nos mais variados níveis.

\section{RESULTADOS ALCANÇADOS E RESULTADOS ESPERADOS NO PROJETO}

A equipe do Projeto Libras L2 já gravou 294 videos-rascunho referentes aos níveis de proficiência, assim distribuídos:

\begin{tabular}{c|c|c|c|c|c|c|c|c} 
A1 & A2 & A2+ & B1 & B1+ & B2 & B2+ & C1 & C2 \\
\hline 25 & 41 & 18 & 44 & 19 & 44 & 18 & 43 & 42 \\
\multicolumn{2}{c}{ Quadro 10: Quantidade de vídeos produzidos para os descritores específicos de cada nível }
\end{tabular}

Fonte: Os autores

Além disso, a equipe também trabalhou na tradução de textos iniciais, com os objetivos do projeto, a descrição geral de cada nível e a descrição geral das atividades linguísticas em cada nível, conforme mostra o Quadro 11.

\begin{tabular}{c|c|c} 
Texto Introdutório & $\begin{array}{c}\text { Descrição Geral } \\
\text { dos Niveis }\end{array}$ & $\begin{array}{c}\text { Descrição Geral } \\
\text { das Atividades Linguísticas }\end{array}$ \\
\hline 5 & 9 & 30
\end{tabular}

Quadro 11: Quantidade de vídeos produzidos para os textos introdutórios

Fonte: Os autores

No total, portanto, foram, 338 vídeos, traduzidos e gravados ${ }^{6}$. Agora, estamos na fase da revisão da tradução e, posteriormente, será a gravação/edição da versão final, que vai para o Portal de Libras. Da mesma forma, estamos na fase de planejamento das videoaulas para cada nível, que, posteriormente serão gravadas, editadas, revisadas e postadas no Portal de Libras.

Além de propiciar à comunidade de professores e estudantes de Libras como L2 esse rico material, em um portal de acesso livre e irrestrito, o presente projeto também enriqueceu, de modo particular, a formação acadêmica dos professores e estudantes envolvidos, tanto em seu conhecimento sobre a Libras, sobre o ensino de Libras e sobre o processo de tradução para a Libras.

\section{CONSIDERAÇÕES FINAIS}

O quadro de referência de Libras como L2 servirá como base para a organização do ensino de Libras nos currículos de Letras Libras (na formação de professores e tradutores e intérpretes de Libras e Língua Portuguesa) e Pedagogia Bilíngue (na formação de pedagogos bilíngue em Libras e Língua Portuguesa), além de cursos livres de ensino de Libras como segunda língua. Desde a década de 1990, quando a FENEIS formava instrutores para o ensino de Libras, não havia uma formalização de níveis de referência para o ensino dessa língua. A proposição do quadro de referência apresentado aqui avança nesse sentido, oferecendo uma organização com base em competências e habilidades a serem atingidas pelos alunos na sua aquisição da Libras como segunda língua. Essa proposição contou com as referências do Quadro Europeu Comum de Referência para o Ensino de Línguas e o ProSign, que conta com referências para o ensino de línguas de sinais na Europa.

${ }^{6}$ Sem contar as regravações. 
Além disso, este trabalho resulta também do desenvolvimento de uma metodologia de análise, adaptação e tradução dos materiais propostos para outras línguas aplicados a Libras. O trabalho foi desenvolvido juntamente com professores de Libras, pesquisadores da Libras e alunos de iniciação científica do Letras Libras, bacharelado e licenciatura, contribuindo especificamente para uma proposição que incorpora as especificidades da Libras e das comunidades surdas brasileiras. A equipe integrou um grupo de trabalho com surdos e ouvintes bilíngues garantindo um quadro de referência que reflete aspectos da Libras e das práticas linguísticas e culturais específicas das comunidades surdas brasileiras.

Esse passo é importante no contexto da Documentação da Libras, pois contribui diretamente para a valorização e o reconhecimento dessa língua. No contexto da documentação, o registro das referências propostas em Libras constitui em si um material importante para a socialização e o estudo desta língua. A partir dele, provavelmente, avançaremos ainda mais nas pesquisas do ensino de Libras como segunda língua, instigando também proposições específicas para o ensino de Libras como primeira língua, considerando o contexto de ensino dos alunos surdos.

\section{AGRADECIMENTOS}

Este trabalho foi possível devido ao recurso do Conselho Nacional de Desenvolvimento Científico e Tecnológico - CNPQ (\# 440337/2017-8).

\section{REFERÊNCIAS}

BERNARDINO, E. L.A.; PEREIRA, M. C. C.; PASSOS, R. Estratégias de ensino da língua brasileira de sinais como segunda língua. Revista Trama, v. 14, n. 32, p. 27-39, 2018.

BRASIL. Base Nacional Comum Curricular. Ensino Médio. Documento homologado pela Portaria n ${ }^{\circ} .570$, publicada no D.O.U. de 21/12/2017, seção 1, pág. 146.

BRASIL. Lei Federal n. 10.436, de 24 de abril de 2002. Dispõe sobre a Língua Brasileira de Sinais - Libras e dá outras providências. Brasília, 2002.

BRASIL. Decreto n. 5.626, de 22 de dezembro de 2005. Regulamenta a Lei $n^{\circ}$ 10.436, de 24 de abril de 2002, que dispõe sobre a Língua Brasileira de Sinais - Libras, e o art. 18 da Lei no 10.098, de 19 de dezembro de 2000. Brasília, 2005.

CONSELHO DA EUROPA. Quadro europeu comum de referência para as línguas: aprendizagem, ensino, avaliação. Trad. Maria Joana Pimentel do Rosário e Nuno Verdial Soares. Edições ASA: Lisboa, 2001.

COUNCIL OF EUROPE. Common european framework of reference for languages: learning, teaching, assessment. Cambridge University Press: Strasbourg, 2001.

EUROPEAN CENTRE FOR MODERN LANGUAGES OF THE COUNCIL OF EUROPE (ECML/CELV). Prosign Project Website 2016-2019. Sign languages and the Common European Framework of Reference for Languages. Disponível em: www.ecml.at/prosign. Acesso em: 28 jun. 2020.

FELIPE, T. Libras em contexto. Curso básico. Livro do estudante. 8. ed. Rio de Janeiro: WallPrint Gráfica e Editora, 2007.

FELIPE, T.; MONTEIRO, M. S. Libras em contexto. Curso Básico. 6 ed. Livro do Professor. Brasília: Ministério da Educação, Secretaria de Educação Especial, 2006. 
LEESON, L. et al. ProSign. Sign languages and the Common European Framework of Reference for Languages. Common Reference Level Descriptors. Council of Europe Publishing, European Centre for Modern Languages of the Council of Europe: Strasbourg, Nikolaiplatz 4, 2016. Disponível em: https://www.ecml.at/Portals/1/mtp4/pro-sign/documents/Common-ReferenceLevel-Descriptors-EN.pdf $>$. Acesso em: 28 jun. 2020.

LIBRAS. Portal de Libras. Disponível em: https://portal.libras.ufsc.br. Acesso em: 25 jan. 2021.

LIBRAS. Portal de Libras. 2020. Disponível em: https://libras.ufsc.br/. Acesso em: 25 abr. 2020.

NORD, C. Princípios teóricos: fundamentos tradutológicos. In: NORD, C. Análise textual em tradução: bases teóricas, métodos e aplicação didática. São Paulo: Rafael Zamperetti Copetti Editor Ltda, 2016. p. 21-31.

PIMENTA, N.; QUADROS, R. M. Curso de Libras I. Rio de Janeiro: LSB Vídeo, 2006.

QUADROS, R. M. Documentação da Libras. In: SEMINÁRIO IBERO-AMERICANO DE DIVERSIDADE LINGUÍSTICA, 2014, Foz do Iguaçu. Anais... Brasília: IPHAN - Ministério da Cultura, 2016. v. 1. p. 157-174.

QUADROS, R. M.; NEVES, B. C.; SCHMITT, D.; LOHN, J. T.; LUCHI, M. Lingua Brasileira de Sinais: Patrimônio Linguístico Brasileiro. Editora Garapuvu: Florianópolis, 2019.

ZIPSER, M. E.; POLCHLOPEK, S. A. Introdução aos estudos da tradução. Florianópolis: UFSC, 2009.

\section{(c) (1) $\circledast \odot$}

Recebido em 24/09/2020. Aceito em 26/10/2020. 